\title{
e-interview
}

\section{George Christodoulou}

George Christodoulou is Professor of Psychiatry, President, Hellenic Centre for Mental Health and Research, and Chair, Ethics Committee of the World Psychiatric Association. He trained at Athens University, the Institute of Psychiatry and the Maudsley Hospital, London. His special interests include psychopharmacology, psychiatric ethics and prevention and psychosomatic medicine.

If you were not a psychiatrist, what would you do?

Probably play (or make) music

What has been the greatest impact of your profession on you personally? Helped me to understand (and predict) human behaviour better, including my own behaviour.

\section{Do you feel stigmatised by your} profession?

No. I don't like this term in this connotation, anyway.

What are your interests outside of work?

Music, reading, cycling, walking, or just spending my time in free association (I can see great benefit in that).

Who was your most influential trainer, and why?

Professor Patrikios, my Professor of Psychiatry when I was a medical student in Athens. Knowledgeable, poetic, theatrical, humorous, an excellent teacher, a bit strange in his behaviour (in keeping with his place of origin - Cephalonia, an island in the lonic sea notorious for its idiosyncratic inhabitants). A very impressive personality.

What job gave you the most useful training experience?

My service in the Hellenic Navy. Being the only medical officer on a warship taught me how to make quick decisions, often under pressure.

Which book/text has influenced you most?

I don't want to sound self-important but, frankly, my own Textbook of Psychiatry for medical students. Writing the book enriched my knowledge as well as my ability to evaluate and balance information and helped me to communicate in a simple and

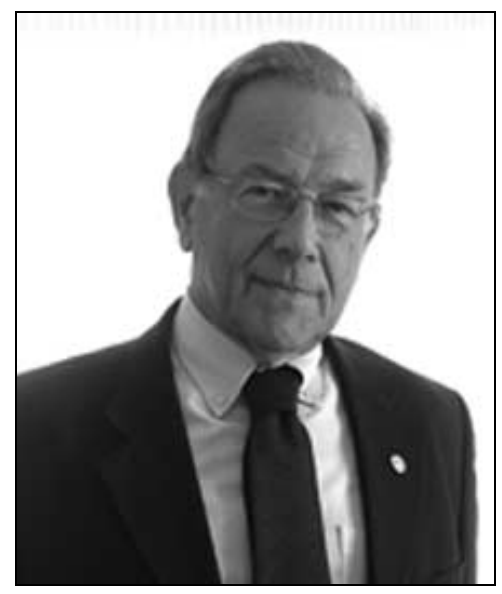

Do you think psychiatry is brainless or mindless?

This is a dichotomy of the past, fortunately.

How would you entice more medical students into the profession?

I would not. There are enough (in Greece). I would focus on quality rather than quantity.

What is the most important advice you could offer to a new trainee?

To learn how to work with others and especially with patients.

What are the main ethical problems that psychiatrists will face in the future?

Psychiatrists will (hopefully) realise that not doing something useful is equally unethical as doing something harmful. Take for example electroconvulsive therapy, an often life-saving treatment that has been practically abandoned because of pressure from the media, prejudice and misinformation.

direct way. It has reinforced my idea that you learn a lot by teaching and the process helps you digest information better (like sleep!)

What research publication has had the greatest influence on your work?

Slater's classic paper on hysteria, which demonstrated that organic states are often hidden behind this diagnosis.

Which part of your work gives you the most satisfaction?

Clinical work.

What do you least enjoy?

Clinical work, again, when it is excessive (also administration and finances).

\section{What is the most promising} opportunity facing the profession?

To utilise constructively the findings of basic science ('from basic science to clinical practice').

What is the greatest threat?

Overspecialisation and overdependence on technology.

\section{What single change would} substantially improve quality of care? A change of attitude of the public towards psychiatric illness.

\section{What conflict of interest do you} encounter most often?

Requests for sick leave when both my patient and I know that the patient is abusing me (and psychiatry).
How would you improve clinical psychiatric training?

By active learning (allocation of responsibility as early as possible).

What single change to mental health legislation would you like to see? A simplification of the procedure of admission of a psychiatric patient to hospital.

How should the role of the Royal College of Psychiatrists change? The opening of the College to the international psychiatric community through the international divisions is a very promising step.

What is the future for psychotherapy in psychiatry training and practice? It should be an integral part of training funded by the training authority.

What single area of psychiatric research should be given priority? No priority should be given. If this happened it would deprive psychiatry of its broadness and inclusiveness.

What single area of psychiatric practice is most in need of development? Primary psychiatric prevention, psychiatric ethics, psychosocial consequences of disasters

Dominic Fannon 